\section{Doping destroys the story at the heart of cycling}

SIR — Suggesting that the Tour de France should lead the way for other sports by permitting drug enhancement, as your recent Editorial 'A sporting chance' (Nature 448, 512; 2007) does, misses an important point. You fail to recognize the reason why people drive 10 hours to watch the regional final of college basketball, wake up in the middle of the night to watch the inevitable penalty shoot-out at the end of an England World Cup football match or even hop on the fast train to see the yellow jersey lead the Tour de France on to the Champs-Élysées. Genuine fans of sport don't just follow their teams to see sportsmen and sportswomen make great plays; they do so to see stories unfold.

To understand why pharmacological enhancements should never be allowed in cycling, you need to understand that all spectator sports thrive by selling simple stories to their fans. The cycling story is that, with great talent and after years of training, the best riders ride faster than the others at the very limits of natural human endurance. In the Tour de France, this story has been told and retold for 100 years - over stages, tours and careers. It describes the overall winner, the best hill climber and even the failed solo breakaway.

How could cycling's story survive if pharmacological enhancements were allowed? Even if the time comes when botulinum toxin injections are available from vending machines, doping should never be allowed in cycling.

Steven Riley

Department of Community Medicine and School of Public Health, Faculty of Medicine, University of Hong Kong, Hong Kong Special Administrative Region, People's Republic of China

\section{Doping: drugs misused for sports put athletes at risk}

SIR - While suggesting that we allow the use of performance-enhancing drugs in competition sports, your Editorial 'A sporting chance' (Nature 448, 512; 2007) assumes that by the end of this century the unenhanced body and mind may be "vanishingly rare" in the general population. As a pharmacologist I disagree. Most pharmaceutical compounds in current use are, or have been, developed to correct pathological processes and not to enhance body functions.

There is no accepted drug treatment to improve superior intellectual activities. Most drugs that increase physical performance in sports do so with serious side effects. For example, liver and heart damage can result from chronic use of anabolic steroids to build muscle, erythropoietin (manufactured to treat anaemia but misused to increase endurance) can cause thrombosis, and the use of stimulants or fatigue retardants can lead to cardiovascular problems.

Given the economic and societal pressure pushing athletes to victory at all costs, introducing leniency towards drug treatment would create wild drug experimentation in all sports, exposing athletes (and possibly young people involved in non-competitive sports) to unknown and potentially severe health risks. To my knowledge, the rule primum non nocere - first, do no harm - has not yet been abolished for the medical professions.

Piero Dolara

Department of Pharmacology, University of Florence, Viale Pieraccini 6, 50139 Firenze, Italy

\section{Life on Mars may be hidden like Earth's extremophiles}

SIR - Your News Feature 'Secrets of the martian soil' (Nature 448, 742-744; 2007) addressed the implications of the next Mars mission finding organic molecules, or not, on the surface of Mars. But the question of whether there are organics on the planet's surface, although important, is not necessarily relevant to whether there is, or was, microbial life on Mars.

With an absolute maximum reach of a metre, the Phoenix mission may do better than Viking (which in 1976 dug down about 6 centimetres). But even if the top metre is sterile, that doesn't indicate whether the planet as a whole is bereft of life.

If life had developed during the planet's first billion years, it and any accompanying organics would have had to survive billions of years of meteorite bombardments, exposure to high levels of ultraviolet and cosmic radiation, and perhaps a highly oxidizing environment. Even if life evolved to withstand such extreme conditions and managed to survive near the surface in some regions, Phoenix is surveying only one point on a planet with a dry-land area equal to that of Earth's.

Only in the past couple of decades has the extent to which life on Earth has colonized, evolved and thrived in a variety of deep ecosystems become evident. For example, recently a thermophilic anaerobic member of the genus Bacillus was obtained from a depth of about 2,700 metres below the surface in Virginia. If Earth is any guide, the question of life on Mars will remain very open until we have at least explored all the areas on Mars equivalent to those on Earth where life has been found.

Samuel Kounaves

Phoenix Mars Scout Mission and Department of Chemistry, Tufts University, Medford, Massachusetts 02155, USA

\section{Turning up the heat on scientific accuracy}

SIR - In your News Feature on the search for organic molecules in martian soil 'Secrets of the martian soil' (Nature 448, 742-744; 2007), you say that the mass spectrometer on NASA's Phoenix lander will be used on "samples heated as high as $1,000^{\circ} \mathrm{C}$ - twice the temperature of Viking's ovens", which is defined as $500{ }^{\circ} \mathrm{C}$. Of course, the former temperature is only about $65 \%$ higher than the latter, since absolute zero is $-273^{\circ} \mathrm{C}$. Although this is not a big mistake, it does not aid the understanding of scientific fundamentals by the general public.

Alexandros Kiupakis

Institute of Molecular Biology and Biotechnology, Foundation for Research and Technology Hellas, Vassilika Vouton, PO Box 1527, Iraklio,

Crete 71210, Greece

\section{Olduvai fossils need more than one research team}

SIR - Your News story 'War of words erupts over fossil dig' (Nature 448, 12; 2007) about the conflict between two research teams at the Olduvai Gorge site in Tanzania gives a partial account of the situation. Contrary to what it states, our team never probed trenches that the Olduvai Landscape Paleoanthropology Project (OLAPP) group had already dug.

The article also fails to clarify that in August 2006, a commission including Tanzanian academics and representatives from the Tanzanian Commission for Science and Technology, the Department of Antiquities and the Ministry of Natural Resources and Tourism declared that there was no scientific overlap between our project and that of the OLAPP group, and that both teams should be allowed to work at the gorge.

Every year erosion exposes hundreds of new fossils that will be lost to science for ever because of the limited power of a single team to undertake proper research along $25 \mathrm{~km}$ of deposits spanning $100 \mathrm{~m}$ of depth. Twenty-first-century palaeoanthropology must overcome this feudal approach to sites if it is to provide knowledge and preserve the human evolutionary heritage for future generations. Manuel Domínguez-Rodrigo ${ }^{\star}$, Audax Mabulla†', Henry Bunn $\%$

*Department of Prehistory, Complutense University, c/Prof. Aranguren s/n, 28040 Madrid, Spain

$\uparrow$ Archaeology Unit, University of Dar es Salaam, PO Box 35050, Dar es Salaam, Tanzania Department of Anthropology, 5240 Social Science Building, 1180 Observatory Drive, University of Wisconsin, Madison, Wisconsin 53706, USA 